\title{
Effects of the Federal Immunization Initiative on the American Health Care System
}

\author{
ROBERT J. SCHLEGEL
}

Charles R. Drew Postgraduate Medical School, Los Angeles, California, USA

Like all federal programs directed at solving a single health care problem, the immunization initiative may have both beneficial and harmful effects on that loose fabric of American institutions sometimes termed "the health care delivery system." It is worthwhile examining these effects, because the system influences a much broader range of health problems, and because it comprises, in the aggregate, one of the nation's largest sources (if not the largest source) of economic and social power (4).

Beneficial results can be expected from the emphasis on public involvement, and from the generation of a better-organized professional response to the need for childhood immunization. For example, the grant awarded jointly to the National Council of Negro Women and the National Medical Association, as will be reviewed by Dr. Gertrude T. Hunter, assures a more effective use of the spirit of volunteerism and self-help than is usual in approaches to meeting the health needs of minority communities. Likewise, the initiative encourages cooperation between health departments and other professional organizations, resulting in the adoption of uniform immunization records and joint treatment programs.

Unfortunately, the initiative may also have deleterious consequences on both the public and the private health care sectors. It is concerned with but one need and fails to respond to the more fundamental flaw in our system that must be corrected to assure long-term success in providing immunizations and other primary health care services. The initiative favors the reemergence in metropolitan health care systems of the old-fashioned public health approach, with its part-time special clinics for venereal disease, tuberculosis, or immunizations, instead of systems providing full services by full-time and well-trained health care professionals. In the private sector, these categorical health programs encourage the proliferation of profit-making vendors who contract for similarly narrowly-defined services, rather than overall health care, with public institutions such as local public school systems.

The health care fields provide more than six million of the 90 million jobs in America (6). Further, most are in the form of career employment in one of more than 400 health professions (1). Included are positions in services, education, research, and administration. The existence of a major health care institution can by itself bring social and economic vitality to a community (2).

Copyright (ㅇ 1979 International Pediatric Research Foundation, Inc. $0031-3998 / 79 / 1305-688 \$ 02.00 / 0$
Hence, it is appropriate to ask how much this vast enterprise contributes to the quality of life, and how fair is the distribution of its services, employment, and career training among the communities and races of America. The answers, of course, are that unnecessary inequities (5) and failures in implementing services that meet the real needs of people are prevalent features (3). These deficiencies are caused, in part, by a public policy based upon a seemingly endless procession of special purpose programs, such as the immunization initiative.

Metropolitan health systems carry out two social functions relevant to the present concern: (1) the delivery of services; (2) the correction of racial inequities in the health care fields. Thus, in Los Angeles County, only 14\% of the population, but $30 \%$ of County employees are black. For many years, hospitals such as the Homer G. Phillips Hospital in St. Louis have trained virtually all of our black radiologic technologists and other skilled allied health professionals. Programs that reduce or neglect the role of inner city, public, and community-based minority health centers slow the progress of assimilating racial minorities into the health care fields. By stimulating replacement of these programs with private providers, the immunization initiative may have just such an adverse effect. By convincing some public policy-makers that it is an adequate response to long-term needs for either immunization resources or other primary care needs, the initiative could pose yet another hazard, instead of the intended benefit.

\section{REFERENCES}

1. Goldstein, H. M. and Horwitz, M. A.: Health Personnel. (Aspen, Germantown, Md, 1977).

2. Schlegel, R. J.: Better health sciences through minority participation: the case for community-based minority medical schools. In: Vijaya L. Melnick and Franklin D. Hamilton: Minorities in Science. (Plenum, New York, 1977).

3. Schlegel, R. J.: In: H. Hugh Fudenberg and Vijaya L. Melnick: Formulation of Health Policy in Biomedical Scientists and Public Policy. (Plenum, New York, 1978).

4. Schlegel, R. J.: Racial equity in the health care fields during the coming age of limited technical growth. Biosciences Communications. (In press) 1978.

5. Sullivan, L. W.: The education of Black health professionals. In: H. Hugh Fudenberg and Vijaya L. Melnick: Biomedical Scientists and Public Policy. (Plenum, New York, 1978).

6. Throckmorton, W. and Donohue, F. X.: Office of Policy Evaluation and Research Employment and Training Administration. Department of Labor. (personal communication, 1978). 